\title{
Dynamic Assessment of Incidental Vocabularies: A Case of Iranian ESP Learners
}

\author{
Sepideh Hanifi (Corresponding author) \\ Department of English Language, Faculty of Humanities, University of Zanjan, Zanjan, Iran \\ E-mail: s.hanifi@znu.ac.ir \\ Mahdi Nasiri \\ Department of English Language, Faculty of Humanities, University of Zanjan, Zanjan, Iran \\ E-mail: mahdinasiri@znu.ac.ir \\ Hesamuddin Aliasin \\ Department of English Language, Faculty of Humanities, University of Zanjan, Zanjan, Iran \\ E-mail: hesamaliasin@znu.ac.ir
}

Doi:10.7575/aiac.alls.v.7n.2p.163

URL: http://dx.doi.org/10.7575/aiac.alls.v.7n.2p.163
Received: $26 / 11 / 2015$

Accepted: 20/01/2016

\begin{abstract}
Dynamic assessment (DA), stemmed from both Vygotsky's (1978) learning theory and Feuerstein's (1979) theory of mediated learning experiences, is an alternative to static assessment. It focuses on both instruction and assessment aiming at promoting learning through mediation. DA has been widely researched in different linguistic areas, but there is paucity of research on its practice in ESP contexts. Accordingly, this study investigated the effectiveness of DA on incidental vocabularies emerging in technical reading textbooks, written for electronic engineering students. The study employed a quasi-experimental research design. Due to sample selection problems, an intact group of 25 BA electronic students were selected from the University of Zanjan. A pre-test was administered to check whether they had previous knowledge of the target words, incidentally acquired during the reading activity. As for the instrument stage, DA procedures were utilized in order to individualize participants' assessment. Following DA implementation, a post-test similar in content to pre-test, was administered to the same participants. The significance of DA for the enhancement of incidental vocabularies was to make participants aware of the strategies of identifying, evaluating and monitoring vocabularies (Nassaji, 2003) through mediation process. The results indicated that participants' incidental vocabulary learning promoted dramatically using DA, which employed structured hints for the mediation process. The results of this study can inform both teachers and learners to provide a step by step procedure to promote both teaching and assessment of ESP learners' vocabulary.
\end{abstract}

Keywords: Dynamic Assessment, Incidental Vocabulary Learning, ESP Learners, ZPD, mediation

\section{Introduction}

The emergence of Dynamic Assessment in EFL contexts is not a recent phenomenon. But, DA dealing with ZPD of learners is a relative term to be defined. There are numerous definitions for DA in the literature. Leunng (2007) defines dynamic assessment as a new approach to assessment which is based on dynamic interaction between the person who examine and the examinee. In this process, the examiner provides leading questions and prompts so as to mediate the examinee. Dynamic assessment, being a subdivision of formative assessment, is based on Vygotsky's socio-cultural principles and is an alternative to static assessment. As Lidz and Gindis (2003, p. 99) suggest, DA is an "approach to understanding individual differences and their implications for instruction that embeds intervention within the assessment procedure."

According to Haywood and Lidz (2007, p. 1) DA is "an interactive approach to conducting assessments... that focuses on the ability of the learner to respond to intervention." In fact, DA focuses on interventions that ease the learning process (Lidz, 1991). DA is distinctly different from static assessments. The results of traditional assessment or nondynamic assessment only reveals the abilities that have been already developed; however, the dynamic score and the analysis of the Zone of Proximal Development (ZPD) makes it possible to find out about the abilities that have not developed yet, but can be developed in collaboration with a more knowledgeable person (Ajideh, Farrokhi, and Nourdad, 2012).

English for Specific Purpose (ESP) courses have always felt the need for teaching specialized/technical vocabulary since 1960's, when it first emerged (Nito, 2004). It is important to note that vocabulary is the core of ESP courses; thus, teaching specialized vocabulary to ESP learners has been a concern throughout the history of ESP and language teaching. To this end, in this study, the attempt was made to recruit the instructional dimension of DA for ESP 
vocabulary acquisition. Since there are different layers of vocabulary acquisition, incidental vocabularies were chosen as the target of this study to be deeply scrutinized. Therefore, the following research question and its related hypothesis were formulated for present piece of research.

\section{Literature Review}

\subsection{Dynamic Assessment}

\subsubsection{Theoretical basis of DA}

Dynamic assessment is theoretically based on two psychologists' work; it is based on Vygotsky's socio-cultural theory and zone of proximal development (ZPD) and Feuerstein's structural cognitive modifiability theory and mediated learning experience (MLE). Based on Vygotsky's (1978) definition, ZPD is the distance between a child's actual developmental level, autonomous problem solving and the higher level of latent development, problem solving under adult guidance or in collaboration with more capable peers. Tzuriel (2001) defines MLE as an interactional process in which parents manipulate adult-child interactions in order to trigger child development.

\subsubsection{Dynamic vs. static assessment}

DA is an alternative to static assessment. The differences between the two types of assessment are in terms of their testing goals, orientation, context of testing, and interpretation of results (Carney and Cioffi, 1992). First, the goal of DA is assessment of change but SA evaluates static performance. Second, DA's orientation is learning process, while SA's orientation is end products. Third, the context of DA is dynamic, open and interactive; however, the context of SA is standardized, structured and formal. Fourth, DA interprets results subjectively and the peak performance is considered, but SA interprets results objectively and the average performance is considered.

\subsubsection{Different approaches to DA}

There are two approaches toward DA, resulting from the two different interpretations of ZPD. The first interpretation is quantitative leading to interventionist DA and the second one is qualitative interpretation of ZPD, leading to interactionist DA.

A preset list of prompts and feedback for each item is provided to examiners during the test administration in the interventionist approach. Lantolf and Poehner (2004a) believe that this approach is psychometric-oriented and is not done for the purpose of enhancing learning. Poehner (2008) defines interventionist DA as the model in which all hints and prompts are prearranged from the most explicit to the most implicit in which the mediator does not react to the learner's needs, but rather s/he follows those highly scripted mediational forms (Hassaskhah and Javan Haghparast, 2012).

Vygotsky's second qualitative interpretation of ZDP brought about the second approach to DA called interactionist. Interactionist approach to DA puts emphasis on learning over assessment. Feuerstein, one of the leading advocates of interactionist DA, argues that if appropriate forms of interactions and instructions are provided, cognitive abilities can be developed (Poehner and Lantolf, 2005). In this approach, it is not the preordained prompts or hints that direct assessors' reaction, rather $\mathrm{s} /$ he responds on the basis of the learners' needs throughout the DA procedure. In this approach, the examiner cooperates with the learners so as to complete a specific task or test (Poehner, 2008).

A difference between the two aforementioned approaches is that mediational hints of the interactionist approach are not scripted and thus, standardized. Therefore, it rests on the examiner's preparation as well as his understanding of the learner's ZPD, because the mediations are formulated in the face of observing learners' needs (Lantolf and Poehner, 2004a).

\subsubsection{Mediation}

According to Poehner (2008), Vygotsky and his colleagues developed what has come to be known alternatively as sociocultural theory, social historical theory, cultural psychology, and cultural historical psychology. The basic tenet of Vygotsky's theory is that human cognition is mediated socially through interaction with others and culturally through the use of cultural objects (Cole and Engestrom, 1993; Vygotsky, 1986; Wertsch, 1985). The basic idea is that engaging in activities that are mediated by others and by cultural objects paves the way for individuals to learn faster.

Mediation in the case of L2 learning can adjust and modify learning actions that were first unfocused. Therefore, as Donato and MacCormick (1994) state mediation is the instrument of cognitive change and learning. Since responsiveness to mediation offers valuable insights into learners' future development, it is crucial for understanding cognitive ability.

\subsubsection{Empirical works on DA}

In recent years DA has attracted the attention of many scholars in the world, and Iranian scholars are rot exceptions. For example, Mardani and Tavakoli (2011) investigated the effect of interactionist DA on 30 Iranian male students and after calculating their performance using t-test, concluded that students' performance had significant improvement after implementation of DA. In another paper written by Jafary, Nordin and Mohajeri (2012), the effect of dynamic assessment on learners' syntactic knowledge of pre-university male learners was examined and compared with static assessment and it was concluded that DA outperformed SA in improving syntactic knowledge of learners. In their quasi-experimental research, Hassaskhah and Javan Haghparast (2012) compared the effect of the two main models of DA on the improvement of the writing abilities and attitudes of EFL learners and concluded that none of them can be given priority; just the situation in which they can be used is different. Birjandi, Estaji and Deyhim (2013) also conducted a research and explored the feasibility of development and implementation of dynamic assessment procedure in the areas of EFL reading comprehension and metacognitive awareness of reading strategy and suggested that DA is 
an effective tool to understand the learners' abilities and to help them success in facing up to reading problems or difficulties. Ajideh and Nourdad (2013) wrote a qualitative paper and presented the advantages of applying DA for identifying the individual EFL learners' reading comprehension ability and proved that DA has a more detailed view over assessing abilities and is efficient in identifying the exact scope of ability for each person.

Nirmalakhandan (2012) investigated a computer-based DA system and suggested that since the implementation of such systems, performance of the students has improved and these systems are preferred by students. Gillam, Pena and Miller (1991) conducted a research studying the role of narration and exposition in gaining literacy and proved that the information that is obtained from DA can be used to distinguish whether a child's low performance is due to her language difference or language impairment. In their quasi-experimental research, Beak and Kim (2003) used three types of concept achievement tests and concluded that DA-based instruction increases children's learning. Orikasa (2010) studied interactionist DA in an L2 context by tutoring L2 English oral communication and investigated how interactions between a mediator and a L1 Japanese student were negotiated. The results indicated that interactionist DA in the L2 context is effective in helping the learner overcome problems and perform better through negotiated interactions with the mediator.

2.2 ESP

Language for Specific Purposes (LSP) has been researched from a long time ago (Dudly-Evans \& St. John, 1998) and since the focus of research is upon English today, English for specific purposes (ESP) has gained ascendency in different fields (Dudly-Evans \& St. John, 1998). "ESP has been referred to as applied ELT as the content and aim of any course is determined by the needs of a specific group of learners" (Dudly-Evans \& St. John, 1998). Iran has not lagged behind from other countries and many researchers have conducted studies on ESP.

Rajabi, Kiany, and Maftoon (2012) investigated the effects of an ESP in-service teacher training program on Iranian ESP practitioners' beliefs and application of instructional tools and also students' achievements. They found that the training program had an influential and beneficial role on the beliefs and practices of ESP teachers.

Alibakhshi, Ghand Ali and Padiz (2011) endeavored to meticulously examine ESP teachers' roles in Iran to see the procedure they follow in their classroom is appropriate or not. The results indicated that Iranian ESP teachers do not teach English and they are not innovative in their teaching and learning.

Amirian and Tavakoli (2009) also studied ESP textbooks offered to students at universities in Iran in terms of their language skills and components and investigated the extent to which these ESP courses have been efficacious in satisfying engineers' job requirements. The results revealed that ESP courses offered in Iranian universities do not suffice to meet the job requirements of engineers.

Sarani and Sahebi (2012) investigated ESP vocabulary learning taught within the paradigm of TBLT. Their findings showed that TBLT was effective in teaching technical vocabularies and could enhance ESP vocabulary learning.

Although ESP has gained importance in Iran and has been under investigation by researchers, ESP is not in a good position in Iran, currently. Some believe that this situation is due to lack of untrained ESP teachers (Rajabi, Kiany, and Maftoon 2012).

\subsection{Incidental vocabulary learning}

In acquiring any language, vocabulary learning is a crucial part and it appears inconceivable that vocabulary can be acquired only through explicit studying and teaching. There is a widely-held belief among teachers and researchers (e.g., Milton, 2009; Hulstijn, 2001) that most L2 vocabulary is acquired incidentally.

2.3.1 Strategies and knowledge sources and learning incidentally

An important point about incidental L2 vocabulary acquisition is that the teacher does not direct the learner's attention to the target words. For example, in Laufer (2006, p. 156), "participants were not told that the purpose of the experiment was vocabulary learning and that they would be tested on vocabulary". However, the learner and not the teacher should decide to attend to the input or not.

When the learner decides to do so, he can resort to two types of tools to infer the meaning of unknown vocabularies, that is, word guessing strategies and knowledge sources (Norzadeh \& Khatib, 2012). A number of researchers (Nassaji, 2003, 2004) have conducted different studies to investigate these two different tools used when learning vocabulary incidentally. Nassaji $(2003,2004)$ identifies three types of word-guessing strategies, i.e. identifying, evaluating, and monitoring, and also five knowledge sources namely grammatical, morphological, world, first language, and discourse knowledge facilitating incidental vocabulary learning. It should be noted that, each strategy is further divided into subtypes and each knowledge source has a detailed explanation that are all beyond the scope of this paper.

2.3.2 Empirical studies on incidental vocabulary learning

In a research by Zeeland and Schmitt (2013), L2 learners' acquisition of three vocabulary knowledge dimensions through listening was investigated and they found that learners start developing knowledge of a word long before they master the form-meaning link.

The concept of incidental learning has been particularly important in the context of research on vocabulary acquisition, which is the core of ESP and therefore both notions will be discussed jointly incorporating DA.

In the same line, a great number of research has been conducted in Iran on dynamic assessment of different general English linguistic areas including vocabulary learning, listening, reading and writing (e.g. Saeidi and Hosseinpour, 2013; Ajideh and Nourdad, 2013; Birjandi, Estaji, Deyhim, 2013; Mardani and Tavakoli, 2011). However, there is paucity of research on DA and ESP, together. To the best knowledge of researchers, there has not been any research on 
dynamic assessment of ESP vocabulary learning. Ample reasons were provided for the start of this work. Accordingly, having acknowledged the importance of vocabulary learning in ESP, this study investigated the effectiveness of DA on incidental vocabularies emerging in technical reading textbooks, written for electronic engineering students, incorporating the two concepts of DA and ESP. Therefore, the research question and the null hypothesis are formulated as follows:

1. Does dynamic assessment improve ESP learners' incidental vocabulary learning?

$\mathrm{H}_{0}$ : Dynamic assessment does not improve ESP learners' incidental vocabulary learning.

\section{Method}

\subsection{Participants}

The participants of this project involved 25 undergraduate students of Electronic engineering studying in the University of Zanjan, during academic year of 2014-2015. The participants chosen had passed their ESP course. They were male and female students and all were native speakers of Persian. It should be noted that gender was not considered as a moderator variable.

\subsection{Instruments and materials}

\subsubsection{The Proficiency test}

Preliminary English Test (PET) was used to homogenize the proficiency level of students. This test was composed of two parts: Reading and Writing. The reading part included five parts with 35 multiple-choice items providing simple written information. The writing section, on the other hand, consisted of three parts with 16 items that the students were asked to do sentence completion, to provide specific information, and to write a letter with the word limit of 100 words. It is important to note that the researchers used just two skills of the PET exam, i.e., writing and reading that were relevant to the purpose of the research. The listening section was not administered due to the impracticalities involved.

3.2.2 Vocabulary tests

The textbook used in the University for ESP course was composed of twenty short passages on different issues in electronics as well as some exercises. The pre/posttest of the incidental vocabularies were extracted from the textbook, written by Manoochehr Haghani in 2013, published by the Organization for Researching and Composing University Textbooks in the Humanities (SAMT).

\subsubsection{Reading passages}

Two passages were chosen from the book mentioned earlier in order to dynamically assess the incidental vocabularies of our intact group. These two passages were the same in terms of their readability and vocabulary profile.

\subsection{Data collection}

After administrating the proficiency test and making the group homogenous, the following procedures were followed. The pre-test of vocabulary from the aforementioned book was administered to the participants. The scores on this test were recorded for further comparison with the results of the post-test. Once the pretest was administered, the researchers tried to go through the meditational steps. According to literature (see for example Poehner, 2008), mediation is the core in dynamic assessment studies. Therefore through some preordained hints, the researchers tried to dynamically assess every single item of the pretest, especially the ones in which participants might commit mistake. The fact of the matter is that the researchers started with those problematic items and through giving hints to them tried to prepare them for a better future performance on the type of vocabularies. An example of a set of hints for an item is provided in Figure 1.

Permeability is ................

a) The property of a magnetizable substance that determines the degree in which it modifies the magnetic flux in the region occupied by it in a magnetic field.

b) The amount of energy that a valence needs to jump from the valence band to the conduction band.

c) The intrinsic silicon crystal having enough energy for some valence electrons to jump in the conduction band.

d) The conductivity of a semiconductor being drastically increased by the addition of impurities.

e) The input signal voltage causing the gate-to-source voltage to swing above and below its Q-point value.

$\mathrm{H} 1$ : That is not the right answer.

$\mathrm{H} 2$ : That is not right either. Look at the use of this word in the following sentence:

There is one class of materials-principally iron and its alloys with nickel, cobalt, and aluminum for which the relative permeability is very many times greater than that of free space.

H3: That is not right either. Look at the following diagram which is a simplified comparison of permeabilities for: ferromagnets $\left(\mu_{\mathrm{f}}\right)$, paramagnets $\left(\mu_{\mathrm{p}}\right)$, free space $\left(\mu_{0}\right)$ and diamagnets $\left(\mu_{\mathrm{d}}\right)$

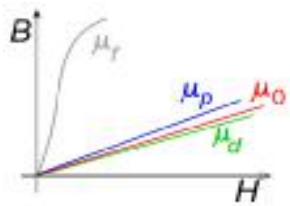

H4: The correct answer was "a". 
The very nature of hints was as being giving hands to predict the right answer for the questions. Therefore, through activating the ZPD of the participants the same procedure, i.e. dynamic assessment of vocabulary items, continued.

An important point to make is that, the procedure of dynamic assessment was done in group size. Once DA was conducted for all the items, the post-test of the vocabulary, extracted from the same book, was administered to the participants. The comparison of the pre and post tests for the sample group indicated whether DA was fruitful or not.

\subsection{Data analysis}

In order to see the effect of DA on incidental vocabulary learning of Electronic students, participants took the post-test as said earlier. As was mentioned, it was after the pretests of vocabulary that participants were exposed to the target treatment (i.e. Dynamic assessment of incidental vocabularies) to experience the effect of DA on their ESP vocabulary learning. Once treatment was over, participants were given posttests for further treatment analysis. The nature of this work was quasi-experimental due to lack of control group within the study. Through a matched T-test the results of pre and post vocabulary tests were compared.

\section{Results}

\subsection{Overview}

As noted earlier, in the study, the attempt was made to scrutinize the effect of dynamic assessment on the incidentalvocabulary learning of ESP students in Iran. As far as the limitations were concerned, an intact group was employed to undergo the coaching phases of DA. Hence, the statistical procedures were adopted in accordance with the design of the research. In other words, to make a clear comparison between the pre-test and post-test of vocabulary, a paired-T-test was used for the same participants. Details related to the statistical analysis are provided in the following lines.

\subsection{Inferential statistics}

Paired sample t-test was used to analyze data collected from pre/post-test. It should be mentioned that, t-test was used since the normality of data was confirmed by Shapiro-Wilk statistical measures $(\mathrm{p}>.05)$ and the results are presented in Table 4.1.

Table 1. Kolmogorov-Smirnov Normality test results

\begin{tabular}{lllllll}
\hline & \multicolumn{2}{l}{ Kolmogorov-Smirnov $^{\mathrm{a}}$} & \multicolumn{3}{l}{ Shapiro-Wilk } \\
\cline { 2 - 7 } & Statistic & Df & Sig. & Statistic & Df & Sig. \\
\hline Pretest scores & .183 & 24 & .030 & .959 & 24 & .403 \\
\hline Posttest scores & .176 & 24 & .064 & .947 & 24 & .259 \\
\hline
\end{tabular}

*. This is a lower bound of the true significance.

a. Lilliefors Significance Correction

After ascertaining the normality of data, participants' mean scores obtained from pre/posttests were compared using paired sample t-test to determine whether there was a statistically significant mean difference between post/pretests. It is noteworthy that the scores obtained from the test were out of 20. The descriptive statistics are presented in Table 4.2.

Table 2. Descriptive statistics of paired-sample t-test

\begin{tabular}{llllll}
\hline & Mean & N & Std. Deviation & $\begin{array}{l}\text { Std. } \\
\text { Mean }\end{array}$ & Error \\
\hline pretest scores & 16.94 & 25 & 10.474 & 2.095 & \\
\hline posttest scores & 19.26 & 25 & 6.794 & 1.359 & \\
\hline
\end{tabular}

On the basis on Table 4.2, it can be seen that the mean scores had a significant increase after going through the mediational steps. Therefore, DA enhances ESP learners' incidental vocabulary learning.

Table 3. Paired sample t-test

\begin{tabular}{|c|c|c|c|c|c|c|c|c|}
\hline & \multirow{3}{*}{ Mean } & \multirow{3}{*}{$\begin{array}{r}\text { Std. } \\
\text { Deviation }\end{array}$} & \multirow{3}{*}{$\begin{array}{r}\text { Std. } \\
\text { Error } \\
\text { Mean }\end{array}$} & \multicolumn{2}{|c|}{ Paired Differences } & \multirow[t]{3}{*}{$\mathrm{T}$} & \multirow[t]{3}{*}{ Df } & \multirow{3}{*}{$\begin{array}{l}\text { Sig. (2- } \\
\text { tailed) }\end{array}$} \\
\hline & & & & $\begin{array}{l}95 \% \\
\text { Interval }\end{array}$ & $\begin{array}{l}\text { Confidence } \\
\text { of the } \\
\text { Difference }\end{array}$ & & & \\
\hline & & & & Lower & Upper & & & \\
\hline $\begin{array}{l}\text { Pre vocabulary } \\
\text { Post vocabulary }\end{array}$ & 5.32000 & 1.90875 & .38175 & 6.10789 & 4.53211 & 13.936 & 24 & .000 \\
\hline
\end{tabular}


The results revealed that the difference between the pretest and the posttest was statistically significant $[\mathrm{t}(24)=13.936$, $\mathrm{p}<.05]$. Therefore, the null hypothesis is rejected. It indicates that the treatment in the form of dynamic assessment and mediation after pretest has been effective in the vocabulary learning of ESP learners.

Overall, DA proved to be significantly effective in vocabulary learning of ESP learners. One important point to make is that there are other ways of measuring the effectiveness of DA on different linguistic dimensions. One of these ways is to count the number of hints and make frequency tables to see how much of mediation was necessary for a particular item. Consequently, more detailed information can appear. But, in this piece of work, due to time restrictions, the comparison of vocabulary performances was focused.

\section{Discussion and conclusion}

This study focused on alternative assessments, specifically dynamic assessment, targeting Iranian ESP learners' incidental vocabulary learning. It is clear that assessing learners' performance constitutes a crucial part of English language courses. However, most ESP learners look at testing as something frightening and revolting; accordingly, the need for alternative types of assessment on ESP has always been tangible (Hutchinson and Waters, 1987). Static assessment, which is commonly used by teachers in ESP context, can be criticized by educational experts due to its ignorance of learners' potentialities, or technically put, ZPD. Considering the limitations of static assessment and taking into account new trends in language assessment, the present study aimed to touch upon the role of dynamic assessment in incidental vocabulary learning in ESP context.

The analysis of the obtained data reveals that the difference between the performances of the participants, who received treatment in the form of mediation, was statistically significant. In other words, dynamic assessment could improve the vocabulary learning of ESP learners. The results of this study like many DA-based studies (see for example, Amirian and Tavakkoli, 2009; Rajabi, Kiani and Maftoon, 2012; Ajideh and Nourdad, 2013) proved to be significant for both language-learning and teaching. In fact no work, to date, has refuted the effectiveness of DA on different linguistic dimensions.

This study is closer in content to what Saeidi and Hosseinpour (2013) conducted. In their study, the role of DA on vocabulary leaning in general English classes was emphasized. The results of their research demonstrated the positive impact of DA on students' performance. But, the present study, by choosing ESP context, on the one hand, and focusing on incidental vocabularies, on the other, endeavored to provide a new context of research. Correspondingly, this work shed new lights on both testing arena and language teaching/learning.

Therefore, mingling assessment and instruction can be beneficial for vocabulary learning of ESP learners. Processoriented dynamic assessment can improve the vocabulary learning of ESP learners. The researchers firmly believe that adopting DA in ESP classes leads to more involvement of learners in the process of learning. It also increases learners' motivation and reduces the nervousness of taking test. On the other hand, teachers can employ DA to gauge the learners' understanding and awareness and identify the areas that learners need more help.

In conclusion, this study coupled with other studies attested the positive part DA plays in language testing and learning. More studies are needed to concentrate on the attitude of participants on DA. Besides, the role of gender as a control variable should be given more heed.

\section{References}

Ajideh, P. \& Nourdad, N. (2013). Dynamic Assessment Revealing Individual Differences in EFL Reading Comprehension Ability. International Journal of Social Sciences and Education, 3(2), 340-350.

Ajideh, P., Farrokhi, F., \& Nourdad, N, 2012. Dynamic assessment of EFL reading: revealing hidden aspects at different level. World Journal of Education, 2(4).

Alibakhshi, G., Ghand Ali, H., \& Padiz, D. (2011). Teaching and Testing ESP at Iranian Universities: A Critical View. Journal of Language Teaching and Research, 2(6), 1346-1352.

Amirian, Z. \& Tavakoli, M. (2009). Reassessing the ESP courses offered to Engineering students in Iran. English for Specific Purposes, 8(23).

Beak, S and Jin Kim, K. (2003). The effect of dynamic assessment based instruction on children's learning. Asia Pacific Education Review, 4(2), 189-198.

Birjandi, P., Estaji, M. \& Deyhim, T. (2013). The Impact of Dynamic Assessment on Reading Comprehension and Metacognitive Awareness of Reading Strategy Use in Iranian High School Learners. Iranian Journal of Language Testing, 3(2).

Carney, J.J., \& Cioffi, G. (1992). The dynamic assessment of reading abilities. International Journal of disability development and education, 39(2), 107-114.

Cole, M., \& Engestrom, Y. (1993). A cultural historical approach to distributed cognition. In Salomon, G. (Ed.). (1997). Distributed cognitions: Psychological and educational considerations. Cambridge: Cambridge University Press.

Donato, R. \& MacCormick, D. (1994). A Sociocultural Perspective on Language Learning Strategies: The Role of Mediation. The modern Language Journal, 78(4), 453-464. 
Dudley-Evans, T., \& St John, M. J. (1998). Developments in English for Specific Purposes. Cambridge: Cambridge University Press.

Ellis, R. (1999). Learning a Second Language through Interaction. Netherland: John Benjamins publishing.

Gillam, R., Pena, E. \& Miller, L. (1999). Dynamic assessment of narrative and expository discourse. Topics in Language Disorder, 20(1), 33.

Hassaskhah, J. \& Javan Haghparast, M. (2012). A comparative study of the impact of DA models on the writing ability and attitude of Iranian EFL learners. Buckingham Journal of Language \& Linguistics, 5(38).

Haywood, C. H. \& Lidz, C. S, 2007. Dynamic assessment in practice: Clinical and educational applications. New York, NY: Cambridge University Press.

Hulstijn, J. (2001). Intentional and incidental second language vocabulary learning: A reappraisal of elaboration, rehearsal and automaticity. In P. Robinson (Ed.), Cognition and second language acquisition instruction (pp. 258-286). Cambridge: Cambridge University Press.

Hutchinson, T. \& Waters, A. (1987). English for specific purposes: A learning-centered approach. Cambridge, Cambridge University Press.

Jafary, M., Nordin, N. \& Mohajeri, R. (2012). The Effect of Dynamic versus Static Assessment on Syntactic Development of Iranian College Preparatory EFL Learners. English Language Teaching, 5(7).

Lantolf, J. P. \& Poehner, M. E. (2004a). Dynamic assessment of L2 development: Bringing the past into the future. Journal of Applied Linguistics, 1(1), 49- 72.

Laufer, B. (2006). Comparing Focus on Form and Focus on FormS in second language vocabulary learning. The Canadian Modern Language Review, 63, 149-166.

Leung, C. (2007). Dynamic assessment: Assessment for and as teaching? Language assessment quarterly: An International Journal, 4, 257-278.

Lidz, C. \& Gindis, B. (2003). Dynamic assessment of the evolving cognitive functions in children. In A. Kozulin, B. Gindis, V. Ageyev, \& S. Miller (Eds.), Vygotsky's educational theory in cultural context (pp. 293-357), Cambridge: Cambridge University Press

Lidz, C. (1991). Practitioner's Guide to Dynamic Assessment. New York City: Guilford Press

Mardani, M. \& Tavakoli, M. (2011). Beyond Reading Comprehension: The Effect of Adding a Dynamic Assessment Component on EFL Reading Comprehension. Journal of Language Teaching and Research, 2(3), 688-696.

Milton, J. (2009). Measuring second language vocabulary acquisition. Bristol: Multilingual Matters.

Moslemi, F., Moinzadeh, A. \& Dabaghi, A. (2011). ESP Needs Analysis of Iranian MA Students: A Case study of the University of Isfahan. English Language Teaching, 4(4), 121-128.

Nassaji, H. (2003). L2 vocabulary learning from context: Strategies, knowledge sources and their relationship with success in L2 lexical inferencing. TESOL Quarterly, 37, 645-670.

Nassaji, H. (2004). The Relationship between Depth of Vocabulary Knowledge and L2 Learners' Lexical Inferencing Strategy Use and Success. The Canadian Modern Language Review, 61, 107-134.

Nirmalakhandan N. (2012). Improving problem-solving skills of undergraduates through computerized dynamic assessment. Social and Behavioral Sciences, 83, 615 - 621.

Nito, R. (2004). Vocabulary \& ESP: Teaching Business Vocabulary. Retrieved from http://www.scribd.com/doc/46984761/ESP.

Nourzadeh, S., \& Khatib, M. (2012). Incidental L2 Vocabulary Acquisition through Reading comprehension, Issues, Arguments and controversies. Journal of Academic and Applied Studies, 2(2), 1- 11.

Orikasa, M. (2010). Interactionist Dynamic Assessment in L2 Learning: A Case Study of Tutoring L2 English Oral Communication. Retrieved from http://scholarspace.manoa.hawaii.edu/handle/10125/20258

Poehner M. E. (2008). Dynamic Assessment: A Vygotskian approach to understanding and promoting L2 development, New York: Springers.

Poehner, M. E. \& Lantolf, J. P. (2005). Dynamic assessment in the language classroom. Language Teaching Research, 9(3), 233-265.

Rajabi, P., Kiani, G. H. R. and Maftoon, P. (2012). ESP in-service teacher training programs: Dot they change Iranian teacher's beliefs, classroom practices and student's achievements? Iberica 24, 261-282.

Saeidi, M. and Hosseinpour, A. (2013). The Effect of Dynamic Assessment as an Instructional Tool on Iranian EFL Learners' Vocabulary Learning. Journal of basic and applied scientific research, 3(10), 421-429.

Sarani, A. and Sahebi, L. (2012). The impact of task-based approach on vocabulary learning in ESP courses. English Language Teaching, 5(10), 118-128.

Tzuriel, D. (2001). Dynamic assessment of young children. New York: Kluwer Academic/Plenum Press. 
Vygotsky, L. S. (1978). Mind in Society: The Development of Higher Psychological processes. Cambridge, MA: Harvard University Press.

Vygotsky, L. S. (1986). Thought and Language. Cambridge, MS: The Massachusetts Institute of Technology.

Vygotsky, L. S. (1998). The collected works of L. S. Vygotsky. Vol. 6. Robert W. Rieber (Ed.). New York: Kluwer Academic/Plenum Press.

Wertsch, J. V. (1985). Vygotsky and the social formation of mind. F. Smolucha (Ed.) and Trans. Cambridge, MS: Harvard University Press.

Zeeland, H., Schmitt, N. (2013). Incidental vocabulary acquisition through L2 listening: A dimensions approach. http://dx.doi.org/10.1016/j.system.2013.07.012 